\title{
Equivalent Helicobacter pylori infection rates in Lynch syndrome mutation carriers with and without a first-degree relative with gastric cancer
}

\author{
Eline C. Soer ${ }^{1}$ - Laura W. Leicher ${ }^{1}$ - Alexandra M. J. Langers ${ }^{2}$. \\ Paul C. van de Meeberg ${ }^{3}$ • Egbert-Jan van der Wouden ${ }^{1}$. Jan Jakob Koornstra ${ }^{4}$. \\ Marloes Bigirwamungu-Bargeman ${ }^{5} \cdot$ Hans F. A. $\operatorname{Vasen}^{6}$ • \\ Wouter H. de Vos tot Nederveen Cappel ${ }^{1}$
}

Accepted: 21 January 2016 / Published online: 4 February 2016

(C) Springer-Verlag Berlin Heidelberg 2016

\begin{abstract}
Background Patients with Lynch syndrome (LS) are at an increased risk of developing gastric cancer. In 2010, a guideline that recommended to screen all patients for Helicobacter pylori was implemented in the Netherlands. H. pylori is an important risk factor in the development of gastric cancer in the general population, and eradication of the bacterium reduces this risk. We aimed to assess the proportion of LS patients being tested and the yield and also addressed the question whether $H$. pylori infection is more prevalent in LS families with known cases of gastric cancer. Methods Proven mutation carriers from five different Dutch hospitals were included. The implementation of $H$. pylori screening and its outcome was examined. The observation period was 2008-2013. The presence of first-degree family
\end{abstract}

Eline C. Soer

e.c.soer@amc.uva.nl

1 Department of Gastroenterology and Hepatology, Isala Clinics, Zwolle, The Netherlands

2 Department of Gastroenterology and Hepatology, Leiden University Medical Center, Isala Clinics, P.O. box 10400, 8000 GK Zwolle, The Netherlands

3 Department of Gastroenterology and Hepatology, Slingeland Ziekenhuis, Doetinchem, The Netherlands

4 Department of Gastroenterology and Hepatology, Groningen University Medical Center, Groningen, The Netherlands

5 Department of Gastroenterology and Hepatology, Medisch Spectrum Twente, Enschede, The Netherlands

6 The Netherlands Foundation for the Detection of Hereditary Tumors, Leiden, The Netherlands members with gastric cancer was noted, and it was observed if $H$. pylori infection was more prevalent in Lynch families with known cases of gastric cancer. Obtainable endoscopy reports were reviewed.

Results Four hundred forty-three (male, 184) proven mutation carriers were included. The proportion of patients screened increased after 2010 , from 37 to $68 \%$. Twenty percent of the patients were infected. The 25 patients who had a firstdegree family member with gastric cancer did not have a higher infection rate. In $30 \%$ of cases, an endoscopy was performed; in four patients, intestinal metaplasia and in eight patients, gastric cancer was found.

Conclusion The recommendation to screen for $H$. pylori is increasingly followed. The prevalence of infection in this patient group does not differ from the general population. Patients who had a first-degree family member with gastric cancer did not have a higher infection rate.

Keywords Lynch syndrome - Gastric cancer .

Helicobacter pylori

\section{Introduction}

Lynch syndrome (LS) is an autosomal dominantly inherited syndrome, caused by germ-line mutations in one of the four mismatch repair (MMR) genes (MLH1, MSH2, MSH6, PMS2) or epigenetic inactivation of MSH2 through an EpCAM mutation [1]. Patients with LS are at an increased risk of developing cancer, particularly colorectal cancer and endometrial cancer. Cancers of the stomach, small intestine, liver, gallbladder ducts, upper urinary tract, brain, and skin are observed more frequently as well [2-4]. 
The lifetime risk of gastric cancer is estimated between 2 and $13 \%$ for LS patients. The 5 -year survival rate for gastric cancer is only $15 \%$ [5]. There is no evidence for clustering of gastric cancer within specific families [2, 6, 7]. The risk appears to be highest for MLH1 and MSH2 mutation carriers. The mean age of diagnosis of gastric cancer is 56 years. Higher risks are reported in countries that have other risk factors for gastric cancer such as high incidence of Helicobacter pylori infection. This indicates that environmental factors also play a role in the development of gastric cancer in gene carriers [8].

Intestinal-type adenocarcinoma is reported in $73-79 \%$ of gastric cancer cases in patients with LS $[6,9]$. This type of cancer is strongly associated with environmental factors, especially $H$. pylori infection. Patients with $H$. pylori-associated chronic gastritis may develop atrophy of the gastric mucosa, followed by intestinal metaplasia. Eventually, adenocarcinoma of the 'intestinal' type can arise [10]. H. pylori is classified by the WHO as a group one carcinogen [11]. In contrast, diffuse-type adenocarcinoma is not known to be associated with environmental factors. This type of cancer is notoriously difficult to detect in its early stages.

In 2013, a group of European experts (the Mallorca group) published its revised guidelines for the clinical management of Lynch syndrome [12]. In light of the relatively low risk of gastric cancer and the lack of established benefits, they did not recommend endoscopic surveillance of the upper gastrointestinal (GI) tract. However, they recommended to screen MMR mutation carriers for the presence of H. pylori infection and to perform subsequent eradication. For Dutch physicians, the recommendation to screen for $H$. pylori had already been operative since 2010 [13].

To date, there are no data on the results of this recommendation. The aims of the present study were to assess (1) the proportion of LS patients being tested for H. pylori infection, (2) the yield of H. pylori screening, and (3) the results of upper GI endoscopy if performed. We also address the question whether H. pylori infection is more prevalent in Lynch families with known cases of gastric cancer.

\section{Material and methods}

In this retrospective observational cohort study, we examined the medical records of Lynch patients from five Dutch hospitals. Patients were eligible for inclusion if they were proven mutation carriers. The observation time was from December 2008 until December 2013. The study was approved by the ethics committees of the respective centers. The implementation of $H$. pylori screening, the type of test (serology, rapid urease test), urea breath test (UBT), stool antigen test or histology and its outcome were examined within the observation period. No data was available on the specific type of $H$. pylori strain. Unfortunately, due to the retrospective nature of the study, it was impossible to discern if the test was undertaken for screening purposes or due to the presence of symptoms. However, we assume that in the vast majority of the patients, the test was done for screening purposes. The presence of first-degree family members with gastric cancer was evaluated; the reports of upper GI endoscopy were collected and reviewed. Patients were excluded in case of incomplete medical records, i.e., if two major parameters were unknown.

\section{Results}

\section{Baseline characteristics}

In total, the medical records of 443 (male, 184) proven mutation carriers were reviewed. The mean age was fifty-three (range, 22-90 years). Twenty-three patients had died. There were almost equally as many MLH1, MSH2, and MSH6 mutation carriers (Table 1).

\section{H. pylori screening}

Screening for H. pylori was performed in 206 mutation carriers $(46 \%)$. A total of forty-two $(20 \%)$ patients were found to be infected. Serological testing was performed most often. For three mutation carriers, the type of test that was performed could not be determined (Table 2).Of the patients ascertained to be mutation carriers before 2010, $37 \%$ was screened for H. pylori. After 2010, the percentage increased to $68 \%$. The percentage of mutation carriers screened varied across the five different hospitals, from 68 to $37 \%$.

Table 1 Baseline characteristics of all mutation carriers

\begin{tabular}{llll}
\hline Characteristic & Total, $n$ & Percentage & Gastric cancer, $n$ \\
\hline All & 443 & & 8 \\
Gender & & & \\
$\quad$ Male & 184 & 42 & 5 \\
$\quad$ Female & 258 & 58 & 4 \\
Alive & & & \\
Yes & 421 & 95 & 5 \\
No & 22 & 5 & 4 \\
Mutation status & & & \\
MLH1 & 125 & 28 & 1 \\
MSH2 & 140 & 32 & 6 \\
MSH6 & 128 & 29 & 1 \\
PMS2 & 34 & 8 & - \\
EpCAM & 16 & 4 & - \\
\hline
\end{tabular}


Table 2 Mutation carriers screened for H. pylori

\begin{tabular}{|c|c|c|}
\hline Characteristic & Total, $n$ & Percentage \\
\hline All & 206 & \\
\hline \multicolumn{3}{|l|}{ Hp status } \\
\hline Positive & 42 & 20 \\
\hline Negative & 161 & 78 \\
\hline Unknown & 3 & 2 \\
\hline \multicolumn{3}{|l|}{ Type of test ${ }^{\mathrm{a}}$} \\
\hline Serology & 94 & 42 \\
\hline RET & 21 & 9 \\
\hline UBT & 4 & 2 \\
\hline Stool antigen & 42 & 19 \\
\hline Histology & 55 & 24 \\
\hline Unknown & 6 & 3 \\
\hline
\end{tabular}

\section{Gastric cancer}

Only eight (1.8\%) of 443 mutation carriers were diagnosed with gastric cancer. The mean age at diagnosis was sixty-four (range, 51-84 years). Four of eight patients had died, all within one year of diagnosis. Four patients were still alive after a follow-up of one to eleven years after treatment. Five patients with gastric cancer were MSH2 mutation carriers, one of whom developed diffuse-type gastric cancer. Seven patients were screened for H. pylori: three by serology and four by histology. One patient was found to be infected. Only one patient had a positive family history for gastric cancer.

\section{Family history (first degree)}

For 356 mutation carriers, the family history was available. Twenty-five of them had at least one first-degree family member with gastric cancer, and seven had more than one firstdegree relative with gastric cancer. The infection rate of H. pylori in patients with a first-degree relative was $20 \%$, similar to the total group. The age at diagnosis was known for thirty-one family members; the mean age was fifty-three (range, 16-78 years). Of the twenty-five mutation carriers with a positive family history, twelve had an MSH2 mutation. MSH2 mutation carriers were 1.6 times (95\% CI 0.7-4.4) more likely to have a positive family history, when compared to the other mutation carriers. However, this difference did not reach statistical significance. See Table 3.

\section{Upper endoscopy}

In 132 patients (30\%), upper GI endoscopy was performed. In fifty-six cases (42\%), no abnormalities were found and no biopsy was taken. In seventy-six patients (58\%), one or more biopsies were taken; the results are shown in Table 4.
Table 3 Characteristics of patients with a positive family history for gastric cancer

\begin{tabular}{lcc}
\hline Characteristic & Total, $n$ & $\%$ \\
\hline All & 25 & \\
Type of mutation & & \\
MLH1 & 6 & 24 \\
MSH2 & 12 & 48 \\
MSH6 & 5 & 20 \\
PMS2 & 1 & 4 \\
EPCAM & 1 & 4 \\
Number of family members & \\
One & 18 & 72 \\
Two & 7 & 28 \\
H. pylori status & & \\
Positive & 5 & 20 \\
Negative & 14 & 56 \\
Unknown & 6 & 24 \\
Age of family member at diagnosis & \\
Average & 53 & \\
\hline
\end{tabular}

In $54 \%$ of the cases, the biopsy revealed no abnormalities. Active inflammation was the most commonly found abnormality $(30 \%)$ and was seen significantly more often in $H$. pylori-positive patients (OR 11.0; $95 \%$ CI 3.1-36.0). Intestinal metaplasia was present only in four $(5 \%)$ of the seventy-six patients. Three of these patients were tested negative for $H$. pylori, using serological testing.

\section{Discussion}

This is the first study to report the outcome of $H$. pylori screening in a large series of LS mutation carriers. The study demonstrates that a substantial proportion of mutation carriers are being tested for $H$. pylori. The recommendation to screen for $H$. pylori has been operative since 2010, and the proportion of patients being tested increased from $37 \%$ before 2010 to $68 \%$ after 2010 . However, we cannot rule out that a small percentage of the tests was performed for complaints instead of for screening purposes. Serology and histology were the tests most commonly used. In $20 \%$ of the mutation carriers, H. pylori infection was diagnosed, a proportion that is similar to the general population $[14,15]$. Assuming H. pylori is an important risk factor in the development of gastric cancer in Lynch patients, we expected to find a higher infection rate in mutation carriers with a positive family history, as $H$. pylori clusters within families $[16,17]$. However, a similar percentage of $20 \%$ in the group mutation carriers with and without a positive family history tested positive for $H$. pylori.

H. pylori is a proven carcinogen in the general population. The role of $H$. pylori in the pathogenesis of gastric cancer in 
Table 4 Patient characteristics and results of histological examination of biopsies in seventy-six Lynch syndrome patients who underwent an upper GI endoscopy

\begin{tabular}{|c|c|c|c|c|c|}
\hline Characteristics & Inflammation & $\begin{array}{l}\text { Intestinal } \\
\text { metaplasia }\end{array}$ & $\begin{array}{l}\text { Intestinal-type } \\
\text { adenocarcinoma }\end{array}$ & $\begin{array}{l}\text { Diffuse-type } \\
\text { adenocarcinoma }\end{array}$ & No abnormality \\
\hline All & 23 & 4 & 7 & 1 & 41 \\
\hline \multicolumn{6}{|l|}{ Gender } \\
\hline Male & 7 & 3 & 4 & 1 & 15 \\
\hline Female & 16 & 1 & 3 & 0 & 26 \\
\hline \multicolumn{6}{|c|}{ Type of mutation } \\
\hline MLH1 & 6 & 2 & 1 & - & 11 \\
\hline MSH2 & 8 & 0 & 5 & 1 & 16 \\
\hline MSH6 & 7 & 2 & 1 & - & 13 \\
\hline PMS2 & 2 & 0 & - & - & 1 \\
\hline \multicolumn{6}{|l|}{ Family history } \\
\hline Positive & 4 & 2 & 1 & - & 6 \\
\hline Negative & 17 & 2 & 5 & 1 & 31 \\
\hline Unknown & 2 & - & 1 & - & 4 \\
\hline \multicolumn{6}{|l|}{ Hp status } \\
\hline Positive & 15 & 1 & 1 & - & 6 \\
\hline Negative & 8 & 3 & 5 & 1 & 34 \\
\hline Unknown & - & - & 1 & - & 1 \\
\hline
\end{tabular}

Lynch syndrome is however still unknown. The fact that gastric cancer in mutation carriers occurs more frequently in countries with a higher prevalence of $H$. pylori infection coupled with fact that the incidence of gastric cancer in Western countries has decreased parallel to the decline of $H$. pylori infection, strongly suggest an important role for this bacterium in the carcinogenesis. There exists ample research that underlines the cost-effectiveness of $H$. pylori screening in the general population. A recent meta-analysis showed that even in lowprevalence countries (America, Canada, UK, and Finland), screening the general population for $H$. pylori was costeffective in the prevention of gastric cancer [18]. Taking into consideration the benefit of screening the general population for $H$. pylori in the prevention of gastric cancer, obviously, screening Lynch syndrome patients would also be beneficial.

In our study population, the incidence of gastric cancer and intestinal metaplasia was much lower than expected, only eight of the mutation carriers had a malignancy; four patients had intestinal metaplasia. The majority of these patients were negative for $H$. pylori. Only one of eight patients with a malignancy was found positive. However, it should be noted that using histology to search for $H$. pylori in the presence of intestinal metaplasia or gastric cancer may produce a falsenegative outcome.

A Finnish study examined the value of upper GI endoscopy surveillance in seventy-three MLH1 mutation carriers and thirty-two mutation-negative family members [9]. It showed a substantial proportion of precursor lesions: $H$. pylori infection was observed in $26 \%$, atrophy in $14 \%$, and intestinal metaplasia also in $14 \%$. However, in the control group, similar proportions were found. They concluded upper
GI endoscopy surveillance was likely not beneficial in MLH1 mutation carriers.

The prevalence of stomach cancer in Lynch patients is lower in the Netherlands than in its surrounding countries. Engel et al. reported Dutch patients to be $76 \%$ less likely to develop gastric cancer than German patients [19]. The cause of this difference is unknown. We included only eight patients with stomach cancer. This low incidence $(2 \%)$ is at least partially attributable to the fact that the registries we used were compiled recently, thereby not including those patients which had already died from stomach cancer.

It is well known that the different mutations have a different phenotype. Various studies have observed that MSH2 mutation carriers have a higher risk for gastric cancer than carriers of the other MMR mutations [6, 12]. In our study, almost half of the mutation carriers with a positive family history are MSH2-positive, and of eight patients with gastric cancer, five had an MSH2 mutation. While our sample size is too small to make conclusions, it supports the assumption that MSH2 mutation carriers are at greatest risk for gastric cancer.

In conclusion: a substantial and increasing proportion of mutation carriers is tested for $H$. pylori, and a similar percentage of $20 \%$ in the group mutation carriers with and without a positive family history was tested positive. The yield of upper GI endoscopy for finding precursor lesions for gastric cancer is low, in accordance to previous studies. In light of the low risk of gastric cancer and the low yield of precursor lesions, we do not recommend regular upper GI endoscopy for any of the MMR mutations in countries with a low prevalence of gastric cancer. Our data do not seem to support the recommendation for routine $H$. pylori screening in Lynch syndrome 
patients. It should however be noted that the low incidence of gastric cancer makes a type 2 statistical error likely. Therefore, we think it is presumptuous to make any claims regarding the effectiveness of screening. To answer this question, a large prospective randomized study would be necessary and such a trial would be unethical in a population at an increased risk of gastric cancer. Therefore, we recommend to continue H. pylori screening in Lynch syndrome patients.

Compliance with ethical standards The study was approved by the ethics committees of the respective centers.

\section{References}

1. Lynch HT, de la Chapelle A (2003) Hereditary colorectal cancer. N Engl J Med 348:919-32

2. Aarnio M, Sankila R, Pukkala E et al (1999) Cancer risk in mutation carriers of DNA-mismatch-repair genes. Int J Cancer 12:214-8

3. Koornstra JJ, Mourits MJ, Sijmons RH et al (2009) Management of extracolonic tumours in patients with Lynch syndrome. Lancet Oncol 10:400-8

4. Maul JS, Warner NR, Kuwada SK et al (2006) Extracolonic cancers associated with hereditary nonpolyposis colorectal cancer in the Utah Population Database. Am J Gastroenterol 101:1591-1596

5. Aarnio M, Salovaara R, Aaltonen LA et al (1997) Features of gastric cancer in hereditary non-polyposis colorectal cancer syndrome. Int J Cancer 21:551-5

6. Capelle LG, Van Grieken NC, Lingsma HF et al (2010) Risk and epidemiological time trends of gastric cancer in Lynch syndrome carriers in the Netherlands. Gastroenterology 138:487-492

7. Watson P, Vasen HF, Mecklin JP et al (2008) The risk of extracolonic, extra-endometrial cancer in the Lynch syndrome. Int $\mathrm{J}$ Cancer 123:444-449
8. Park YJ, Shin KH, Park JG (2000) Risk of gastric cancer in hereditary nonpolyposis colorectal cancer in Korea. Clin Cancer Res 6: 2994-8

9. Renkonen-Sinisalo L, Sipponen P, Aarnio M et al (2002) No support for endoscopic surveillance for gastric cancer in hereditary non-polyposis colorectal cancer. Scand J Gastroenterol 37:574-7

10. Correa P (1992) Human gastric carcinogenesis: a multistep and multifactorial process-First American Cancer Society Award Lecture on Cancer Epidemiology and Prevention. Cancer Res 52: $6735-6740$

11. IARC Working Group on the Evaluation of Carcinogenic Risks to Humans (1994) Schistosomes, liver flukes, and Helicobacter pylori. IARC Monogr Eval Carcinog Risks Hum June 61:1-241

12. Vasen HF, Blanco I, Aktan-Collan K et al (2013) Revised guidelines for the clinical management of Lynch syndrome (HNPCC): recommendations by a group of European experts. Gut 62:812-23

13. 13) www.oncoline.nl, erfelijke tumoren, Lynch syndrome, consensus based, 1-7-2010

14. Numans ME, De Wit NJ, Dirven JAM et al (2013) NHG-standaard Maagklachten(Derde herziening). Huisarts Wet 56:26-35

15. Blankenstein V, van Vuuren L et al (2013) The prevalence of Helicobacter pylori infection in the Netherlands. Scand J Gastroenterol 48(7):794-800

16. Demirel BB, Akkas BE, Vural GU (2013) Clinical factors associated with $H$. pylori infection - is there an association with gastric cancer history in first-degree family members? Asian Pacific J Cancer Prev 14:1797-1802

17. Rokkas T, Sechopoulos P, Pistiolas D et al (2010) H. pylori infection and gastric histology in first-degree relatives of gastric cancer patients: a meta-analysis. Eu J Gastroen Hepat 22:1128-1133

18. Lansdorp-Vogelaar I, Sharp L (2013) Cost-effectiveness of screening and treating $H$. pylori for gastric cancer prevention. Best Pract Res Clin Gastroenterol 27:933-947

19. Engel C, Loeffler M, Steinke V et al (2012) Risks of less common cancers in proven mutation carriers with Lynch syndrome. J Clin Onc 30:4409-4415 